Lisa Schwaiger

Gegen die Öffentlichkeit

Digitale Gesellschaft | Band 46 
Lisa Schwaiger (Dr. phil.), geb. 1990, ist Soziologin und Medienwissenschaftlerin am Institut für Kommunikationswissenschaft und Medienforschung (IKMZ) und am Forschungszentrum Öffentlichkeit und Gesellschaft (fög) der Universität Zürich. Ihre Forschungsschwerpunkte sind der Strukturwandel der Öffentlichkeit, digitale (Gegen-)Öffentlichkeiten, Religion und Medien sowie qualitative Forschungsmethoden. 
Lisa Schwaiger

\section{Gegen die Öffentlichkeit}

Alternative Nachrichtenmedien im deutschsprachigen Raum 
Die Open-Access-Ausgabe wird publiziert mit Unterstützung des Schweizerischen Nationalfonds zur Förderung der wissenschaftlichen Forschung.

\section{Bibliografische Information der Deutschen Nationalbibliothek}

Die Deutsche Nationalbibliothek verzeichnet diese Publikation in der Deutschen Nationalbibliografie; detaillierte bibliografische Daten sind im Internet über http://dnb.d-nb.de abrufbar.

\section{(c) (1) $\Theta \Theta$}

Dieses Werk ist lizenziert unter der Creative Commons Attribution-NonCommercial-NoDerivs 4.0 Lizenz (BY-NC-ND). Diese Lizenz erlaubt die private Nutzung, gestattet aber keine Bearbeitung und keine kommerzielle Nutzung. Weitere Informationen finden Sie unter https://creativecommons.org/licenses/by-nc-nd/4.o/deed.de

Um Genehmigungen für Adaptionen, Übersetzungen, Derivate oder Wiederverwendung zu kommerziellen Zwecken einzuholen, wenden Sie sich bitte an rights@transcriptpublishing.com

Die Bedingungen der Creative-Commons-Lizenz gelten nur für Originalmaterial. Die Wiederverwendung von Material aus anderen Quellen (gekennzeichnet mit Quellenangabe) wie z.B. Schaubilder, Abbildungen, Fotos und Textauszüge erfordert ggf. weitere Nutzungsgenehmigungen durch den jeweiligen Rechteinhaber.

\section{() 2022 transcript Verlag, Bielefeld}

Umschlaggestaltung: Maria Arndt, Bielefeld

Druck: Majuskel Medienproduktion GmbH, Wetzlar

Print-ISBN 978-3-8376-6121-7

PDF-ISBN 978-3-8394-6121-1

EPUB-ISBN 978-3-7328-6121-7

https://doi.org/10.14361/9783839461211

Buchreihen-ISSN: 2702-8852

Buchreihen-eISSN: 2702-8860

Gedruckt auf alterungsbeständigem Papier mit chlorfrei gebleichtem Zellstoff. Besuchen Sie uns im Internet: https://www.transcript-verlag.de Unsere aktuelle Vorschau finden Sie unter www.transcript-verlag.de/vorschau-download 